\title{
Comparison of Attitudes of School Administrators and Counselors towards Mandatory Reporting of Suspected Child Sexual Abuse
}

\author{
Aynur Eren-Gumus \\ Assoc. Prof. Dr. \\ Bahçeşehir University \\ Faculty of Educational Sciences \\ Department of Counseling and Guidance \\ Turkey
}

\begin{abstract}
The aim of this study was to compare the attitudes of Turkish school administrators and school counselors towards the mandatory reporting of suspected child sexual abuse and to determine their main support needs in relation to their reporting obligations. Quantitative and qualitative research methods were used in this study. Both groups had high subscale scores which indicated positive attitude, but although the quantitative results suggested that school administrators had a more positive attitude than school counselors, this result was not confirmed by the qualitative analysis. The school administrators did not know the relevant laws and the school counselors thought they were unclear. Both groups had concerns about the consequences of reporting for themselves and children, but only reporter-related factors such ensuring the security of reporters were identified as preconditions for fulfilling their obligation to report CSA. More child-centered reporting policies should be devised and implemented.
\end{abstract}

Keywords: child sexual abuse, mandatory reporting, school administrators, counselors, legal issues, prevention

\section{Introduction}

Child sexual abuse (CSA), an issue which has been neglected for many years, is a traumatic reality for thousands of children throughout the world and is also a serious criminal offence (Sokullu-Akınc1, 2008). CSA tends to be hidden for a number of reasons, including the perpetrators' efforts to ensure secrecy and leave no physical evidence (Allnock, 2010), the child's failure to tell somebody about experiencing sexual abuse (Alaggia, 2004, 2005; Allnock, 2010) and adults' failure to report cases of sexual abuse after they have been informed (Lambie, 2005; Smallbone \& Wortley, 2001).

In many judicial systems around the world it is mandatory for professionals to report suspected CSA (Mathews, 2014). Research has shown that reporting cases of suspected CSA greatly aids the development and implementation of preventive measures (Paine \& Hansen, 2002; Sokullu-Akınc1, 2008; Walsch, Rassafiani, Mathews, Farrel \& Butler, 2012). Mandatory reporting laws, in particular, have been seen as a secondary preventive response to child maltreatment (Mathews, 2014). Reporting CSA is a legal obligation, but less than $10 \%$ of cases worldwide are reported (Lyon \& Ahern, 2011). It is therefore critical that professionals working with children comply with the law on mandatory reporting. School personnel have an important role in detecting and reporting CSA as professionals who spend a significant amount of time with children on weekdays (Kenny \& McEachern, 2002). Moreover it has been reported that in countries where the fight against CSA has been effectively waged, the educators, play a greater role in reporting to the legal authorities (Walsch et al., 2012). A study by Lambie (2005) highlighted the strategic role of school counselors in coordinating the responses of schools to CSA and initiating transformation, whereas Zellman (1990) placed the responsibility to perform this role on school administrators.

In Turkey civil servants have a legal obligation to report CSA to the relevant authority, and this obligation was amended in Article 279 of the TPC (Turkish Penal Code), which states that a civil servant who delays or fails in reporting to the relevant authorities any offense that requires investigation and prosecution on behalf of the public after learning about such an offence in the course of his or her duties will be sentenced to imprisonment for a period ranging from six months to two years. 
This article, along with the relevant regulations and legal sources (Eren, Gumus \& Gumus, 2013; Koca, 2012; Unver, 2012), requires all school personnel to report all suspected CSA to legal authorities (i.e., to the office of the chief prosecutor or law enforcement) immediately, and, in cases where there is a failure to report, school personnel will be sentenced to imprisonment.

\section{The Attitudes of School Administrators and Counselors towards Mandatory Reporting of Suspected CSA}

Even in the USA, the leading country in terms of regulations on reporting CSA (Erbas, 2015), many school counselors fail to report due to uncertainties regarding the process and other problems that are a source of great concern for them (Lambie, 2005). Hermann (2002) reported that the second most common legal problem faced by school counselors is deciding when to report CSA. Goldman and Padayachi (2005) found that the majority of 122 school counselors had a general knowledge of the laws on reporting suspected cases of CSA, but only a minority knew what the laws required them to do. Goldman and Padayachi (2002a, 2002b, 2005) also found that there was a tendency for school counselors not to report CSA. Furthermore, outcomes of various studies conducted with school counselors have indicated that decisions to report cases of suspected CSA are primarily affected by the laws in place and concerns related to student safety (Bryant, 2009; Bryant \& Milsom, 2005), and that counselors' failure to report is influence by lack of evidence regarding the occurrence of abuse (Bryant et al., 2005) and the inadequacy of the reporting system in giving a response (Bryant, 2009; Bryant \& Baldwin, 2010). Studies conducted by Zellman and Bell (1990, cited in Hawkins and McCallum, 2001) indicate that individuals start failing to report cases of suspected CSA when they discover how overburdened intervention services are. Then, faced with the difficulty of finding sufficient evidence, these individuals tend to further neglect their duty to report.

Another significant reason for deciding not to report child abuse is associated with inadequate training on reporting (Goldman \& Padayachi, 2005; Reiniger, Robison \& McHugh, 1995). The literature notes that educators play a leading part in providing information about mandatory reporting (Bryant and Baldwin, 2010; Daro, 2011; Hawkins and McCallum, 2001; Ridgway, 2005). A systematic literature review (Walsh, Rassafiani, Mathews, Farrell, \& Butler, 2010) examined factors potentially relevant to teachers' attitudes towards reporting CSA and identified the key factors as confidence in the system's response to reports and fear that reporting would have negative outcomes (such as negative reactions by the parents, troubles arising as a consequence of reporting and the failure to find sufficient evidence).

The number of comparative studies evaluating the attitudes of school administrators and counselors to reporting of CSA is quite limited. Kenny and McEachern (2002) found that school counselors considered themselves more qualified than administrators in this regard and believed they reported more cases in the course of their professional life. However, the same study indicated that counselors were more inclined to avoid reporting due to the absence of physical evidence and a weak commitment to child care services. Zellman (1990) found that of the professionals who are legally required to report any suspected child abuse and/or negligence (i.e. pediatricians, psychiatrists, psychologists, social workers, babysitters), school principals reported the most cases. Zellman concluded that this pattern of reporting was related to a district (workplace) reporting policy. Zellman also found that the school principals' tendency to report was based on annoying details related to reporting, including personal consequences, like time lost from normal work, risk of legal action and reputational risk, and apprehensions regarding the possible outcomes for the children. Moore's (2017) study also indicated that children and young people think that adults tend to protect other adults and institutional reputations even when CSA occurs.

To date there have been few studies examining the knowledge and attitudes of Turkish school administrators and counselors to suspected CSA. Results from research carried out for a master's degree (Akgul, 2015) indicated that most preschool teachers and administrators were unaware that reporting suspected CSA was a legal obligation. In contrast, Aksel and Irmak (2015) conducted a study with school counselors and teachers and found that most of the participants were aware that reporting suspected CSA was a legal obligation. They reported that $27(53 \%)$ school counselors and 14 (29\%) teachers had faced cases of suspected CSA in their careers, with 18 of the counselors and only one of the teachers reporting the case to the authorities. Almost none of the participants (preschool teachers and administrators) in Akgul's (2015) study had reported cases of CSA; the participants had decided not to report suspected case despite having positive attitudes towards reporting suspected CSA. 
In addition, Akgul (2015) found that many of the preschool teachers had the misconception that the school principal was the person to be notified of suspected cases of CSA. Cetinkaya (2014) reported that $21 \%$ of participating school counselors had experienced an ethical dilemma in relation to their obligation to report CSA cases, and that $40 \%$ of the cases were not reported. A qualitative study of 26 school counselors who had reported CSA (Cetinkaya, 2015) found that school principals were the most commonly cited barrier to reporting (mentioned by 11 participants, $44 \%$ ), with only $20 \%$ of the participants $(n=5)$ perceiving school principals as a source of support. Although this result indicated that the school counselors had more knowledge about and experience with CSA reporting than the school administrators, it does not mean that school counselors attitude to reporting CSA would improve if school administrators were supportive. As Hamilton (2017) emphasized, as long as there is an unquestioned assumption that adults' needs take priority over those of children, there will not be an important change in how adults approach prioritization of children's well-being. This also indicates that the expectations for CSA reporting training programs are not very realistic. Therefore, it is necessary to compare the attitudes of school counselors and school administrators, who are very important for CSA reporting, and to discover whether they prioritize the needs of children or reporters. This information would make it possible to come up with more realistic proposals for educational and legal measures to support CSA reporting. There is a significant relationship between attitude to reporting CSA and behavior when faced with suspected CSA (Walsh et al., 2010). This study compared the attitudes of school administrators and school counselors towards the mandatory reporting of suspected CSA and examined their needs for further educational and legal support. Quantitative methods were used to determine whether attitude to reporting was affected by role (school counselor vs. administrator), receipt of specific training and having submitted a CSA report. Qualitative methods were used to explore counselors' and administrators' opinions about laws, possible consequences of CSA reporting and to determine their main support needs in relation to their reporting obligations.

\section{Methods}

This study used a mixed methods research design. Mixed methods research involves the collection, analysis and interpretation of both qualitative and quantitative research data (Leech \& Onwuegbuzie, 2009). A mixed methods design is used to overcome the deficiencies and limitations of studies that use a single method and to conduct more valid and accurate research (Greene, 2005).

\section{Participants}

Quantitative data were collected from 366 participants (252 women, 114 men) of whom 113 were school administrators ( 39 women, 74 men) and 253 school counselors ( 213 women, 40 men). All participants resided in Istanbul, the most populous city in Turkey. The mean age of the participants was 37.60 years $(S D=15) ; 131$ worked in elementary schools, 127 in secondary schools and 108 in high schools. The majority of participants $(n$ $=217$ ) had received training on reporting CSA, but 149 had not. Ninety-three participants $(74$ school counselors, 19 administrators) had previously reported CSA, whilst 252 had not, and 74 of those who had reported were school counselors, while 19 were administrators. Only 17\% of school administrators had reported a single incidence of CSA during their period in office, compared with $29 \%$ of the counselors. Nineteen counselors had reported two cases and one had reported four cases. Of those who had reported, 72 were female and 21 were male. The qualitative sample consisted of 17 volunteer participants ( 9 school counselors, 8 administrators). Only one person in the qualitative sample (a school counselor) had reported an incidence of CSA.

\section{Instruments}

The Teacher Reporting Attitude Scale for Child Sexual Abuse (TRAS-CSA) developed by Walsch et al. (2010) was used in this study. The TRAS-CSA is a 21-item, self-administered scale based on a systematic literature review that has been subjected to a five-phase validation (Walsh et al., 2010). TRAS-CSA data were evaluated using exploratory factor analysis, which revealed three factors, namely commitment to the reporting role, confidence in the system's response to reports and concerns about reporting. These three factors accounted for $37.5 \%$ of the variance in the 14-item measure. Cronbach's alpha coefficients for the subscales associated with these factors were .769 (commitment), .617 (confidence), and .661 (concerns) (Walsh et al., 2012). The fit of a three-factor model for the 14-item TRAS-CSA (Walsh et al., 2012) to the Turkish adaptation was tested with this study's data collected from the school counselors and school administrators. 
Indices of fit $\left(\chi^{2} / d f=2.45, p<.01\right.$; RMSEA $\left.=0.06, \mathrm{GFI}=.94, \mathrm{AGFI}=.90, \mathrm{CFI}=.89\right)$ were acceptable, with the exception of the CFI (Raykov \& Marcoulides, 2006). Values of Cronbach's alpha for the subscales were as follows, confidence: .63; commitment: .70; concern: .68.

Questionnaire on opinions about reporting suspected CSA. This questionnaire consisted of the following open-ended questions designed to elicit qualitative data: i) 'What are your views about the laws that tell you what to do regarding suspected child sexual abuse?' ii) 'What are the possible consequences, for you personally, of submitting a report on suspected child sexual abuse?' iii) 'What are the possible consequences, for the child, of submitting a report of suspected child sexual abuse?' iv) 'What conditions would need to be met for you to fulfill your responsibility to report suspected child sexual abuse?'

\section{Procedure}

After the necessary permissions were obtained from the Branch Directorates of National Education the data were collected from the volunteer participants who had agreed to complete the instruments prior to CSA conferences held with the school counselors and administrators. School administrators did not give permission for audio recording of their responses, insisting on responding in writing. TRAS-CSA and opinions questionnaire were given at the same time. A doctoral student presented participants with the consent form and data collection instruments at the same time. Participants took approximately 30 minutes to complete the questionnaires. Seventy-seven participants received both tools but returned them without any responses; 306 participants did not respond to any of the open-ended questions and 33 participants who had volunteered to provide answers to these questions answered only some of them. The responses given by the participants to all items were analyzed.

\section{Data Analyses}

Independent-samples $t$-tests were used to assess the effects of role (counselor vs. administrator) receipt of specific training and having submitted a CSA report. The sample size was adequate for $t$-tests. The qualitative data were subjected to content analysis. The transcripts were read thoroughly to obtain detailed data units and codes. The codes were then collected, common points were determined and classification was performed. In the last stage, the common points were determined once again and themes were established. The aim was to find significant relationships between these themes.

Various strategies were applied to confirm the validity and reliability of the study. Initial analysis of the data set was followed by further analysis by a colleague. The qualitative data units were separated into two titles as "difference of opinion" and "agreement of opinion". Codes that were under the "difference of opinion" category were revised through independent analyses to identify possible agreements. The Adaptation Percentage between the Codes formula developed by Miles and Huberman (1994) was used to calculate reliability, and was found to be $87 \%$ in this study. Simsek and Yildirim (2003) stated that an adaptation percentage of over $70 \%$ indicates adequate consistency between coders. In addition, the data from two administrators and counselors were re-coded at two-week intervals to ensure internal reliability. The consistency percentage between the two codes was also calculated using the reliability formula suggested by Miles and Huberman (1994) and was found to be 95\%. In addition, an effort has been made to include all quotations describing each theme in the presentation of the findings.

\section{Results}

Analysis of the TRAS-CSA attitude scores showed that the mean scores for commitment to the reporting role in each group, which is separated according to participants' duty, background of training and reporting, were high, with no significant difference between administrators and counselors. There were, however, group differences in confidence in the system 's response to reports and concerns about reporting. School administrators' confidence $(t$ $=3.01 ; p<.05)$ and concern $(t=2.10 ; p<.05)$ scores were significantly more positive than those of the school counselors. Participants who had reported a case of suspected CSA had higher mean scores for concerns about reporting than those who had not $(t=3.09 ; p<.01)$. Receipt of specific training on CSA reporting did not affect TRAS-CSA scores. These results are presented in Table 1. 
Table 1. Analysis of TRAS-CSA Scores by Group

\begin{tabular}{|c|c|c|c|c|c|c|}
\hline & & $n$ & $M$ & $S D$ & $t$-test & $p$ \\
\hline \multirow[t]{3}{*}{ Duty } & $\begin{array}{l}\text { Commitment } \\
\text { Sch. Admin. } \\
\text { Sch. Counsel. }\end{array}$ & $\begin{array}{l}113 \\
253\end{array}$ & $\begin{array}{l}4.68 \\
4.58 \\
\end{array}$ & $\begin{array}{l}0.37 \\
0.43\end{array}$ & 2.20 & 0.28 \\
\hline & $\begin{array}{l}\text { Confidence } \\
\text { Sch. Admin. } \\
\text { Sch. Counsel. }\end{array}$ & $\begin{array}{l}113 \\
253\end{array}$ & $\begin{array}{l}3.58 \\
3.28\end{array}$ & $\begin{array}{l}0.89 \\
0.87\end{array}$ & 3.01 & $0.03 *$ \\
\hline & $\begin{array}{l}\text { Concerns } \\
\text { Sch. Admin. } \\
\text { Sch. Counsel. }\end{array}$ & $\begin{array}{l}113 \\
253\end{array}$ & $\begin{array}{l}3.93 \\
3.75\end{array}$ & $\begin{array}{l}0.71 \\
0.78\end{array}$ & 2.10 & $0.04 *$ \\
\hline \multirow[t]{3}{*}{ Training } & $\begin{array}{l}\text { Commitment } \\
\text { Trained } \\
\text { Not Trained }\end{array}$ & $\begin{array}{l}217 \\
149\end{array}$ & $\begin{array}{l}4.60 \\
4.64\end{array}$ & $\begin{array}{l}0.42 \\
0.42\end{array}$ & -0.93 & 0.35 \\
\hline & $\begin{array}{l}\text { Confidence } \\
\text { Trained } \\
\text { Not Trained }\end{array}$ & $\begin{array}{l}217 \\
149\end{array}$ & $\begin{array}{l}3.32 \\
3.44\end{array}$ & $\begin{array}{l}0.91 \\
0.84\end{array}$ & -1.24 & 0.22 \\
\hline & $\begin{array}{l}\text { Concerns } \\
\text { Trained } \\
\text { Not Trained }\end{array}$ & $\begin{array}{l}217 \\
149\end{array}$ & $\begin{array}{l}3.84 \\
3.76\end{array}$ & $\begin{array}{l}0.77 \\
0.75\end{array}$ & 0.96 & 0.34 \\
\hline \multirow[t]{3}{*}{ Reporting } & $\begin{array}{c}\text { Commitment } \\
\text { Reported } \\
\text { Did Not Report }\end{array}$ & $\begin{array}{c}93 \\
273\end{array}$ & $\begin{array}{l}4.65 \\
4.60\end{array}$ & $\begin{array}{l}0.37 \\
0.44\end{array}$ & 0.86 & 0.39 \\
\hline & $\begin{array}{r}\text { Confidence } \\
\text { Reported } \\
\text { Did Not Report }\end{array}$ & $\begin{array}{c}93 \\
273\end{array}$ & $\begin{array}{l}3.23 \\
3.42\end{array}$ & $\begin{array}{l}0.99 \\
0.85\end{array}$ & -1.84 & 0.06 \\
\hline & $\begin{array}{r}\text { Concerns } \\
\text { Reported } \\
\text { Did Not Report }\end{array}$ & $\begin{array}{c}93 \\
273\end{array}$ & $\begin{array}{l}4.01 \\
3.73\end{array}$ & $\begin{array}{l}0.74 \\
0.76\end{array}$ & 3.09 & $0.002 * *$ \\
\hline
\end{tabular}

$* p<.05 ; * * p<.01$

Findings regarding the qualitative research questions have been organized by theme and code under three titles. Examples from both school counselors (SCs) and school administrators (SAs) are presented

\section{School Administrators' and Counselors' Views on the Laws Regarding CSA}

Two themes and sub-themes were derived from the answers given to the open-ended questions:

Theme 1. Practicability and comprehensibility of laws. Three sub-themes were present under this theme:

(a) The laws are not executable ( $n=4$; SC 3, SC 4, SC 7, SC 8). I found that the laws are not executable. The police officers and the attorney general were reluctant to cooperate. Nothing happened after I reported (SC 7).

(b) The laws are not comprehensible ( $n=4$; SC 2, SC 6, SC 8, SC 9). I think the laws are inadequate and complicated. I get a different understanding of things every time I read them (SC 2.)

(c) The laws are executed ( $n=1 ;$ SA 8). I have seen that recently the laws have been executed and severe sanctions imposed. I consider this approach very appropriate.

The sub-themes the laws are not executable and the laws are not comprehensible were derived from statements made by counselors. The only positive sub-theme, the laws are executed, was derived from a statement made by a school administrator.

Theme 2. Knowledge about the laws and executing the laws. There were two sub-themes under this theme:

(a) No knowledge about the relevant laws ( $=$ 9; SC 1, SC 4, SC 5 / SA 1, SA 2, SA 4, SA 5, SA 6, SA 7). I do not have knowledge about where, how and when to report. I also do not know about other regulations (SA 1).

(b) Failing to implement laws despite being aware (n=2; SC 3 / SA 3). I do not want to experience what my colleagues who reported experienced. I know about the laws but the laws, by their nature, do not protect us (SC 3) 
Two of the sub-themes under this theme have negative content. Three of the statements under the sub-theme no knowledge about the relevant laws was made by counselors and six by school administrators. The sub-theme failing to implement laws despite being aware was derived from the statements of a counselor and an administrator.

\section{School Administrators' and Counselors' Perceptions of the Consequences of Reporting Suspected CSA}

Sub-themes were defined under two themes generated from answers given to the open-ended questions:

Theme 1. Possible results for the reporters. There are three sub-themes under this theme:

(a) Threats from the family ( $n=15$; SC 1 , SC 2, SC 3, SC 5, SC 6, SC 7, SC 8, SC 9 / SA 1, SA 2, SA 3, SA 4, SA 5, SA 8). I had to deal with threats from the child's family when I submitted a report before. But I think these threats and reactions are not important given what the child was exposed to (SC 9). The family may consider the report as slander and seek revenge ( $S A$ 1).

(b) Social pressure ( $n=3$; SC 6 / SA 2, SA 8). I fear the possible condemnation of the people around me (SA 2).

(c) Children denying the abuse ( $n=2$; SC 4 / SA 8). The child might deny his or statements during the trial. Then I would be in a difficult position (SC 4).

All the sub-themes defined under this theme were negative. Nearly all participants $(n=15)$ endorsed the subtheme threats from the family, the exceptions were a counselor and two administrators. Statements from only three participants were allocated to the social pressure sub-theme, and there were statements from two participants under the children denying the case sub-theme.

Theme 2. Possible results of reporting for the child. Four sub-themes were defined under this theme:

(a) Executers of legal procedures harming the children $(n=8$; SC 3, SC 6, SC 7 / SA 1, SA 2, SA 3, SA 6, SA 8), When the law is applied, the child's well-being is not taken into consideration. Children are especially hurt when their statements are taken (SC 7). Children who are taken away from their homes and placed in an institution may encounter psychological problems. Not enough studies have been conducted on this matter (SA 1).

(b) Families acting in a punitive manner ( $n=5$; SC 4, SC 5, SC 8, SC 9 / SA 1). Families cannot accept the truth and put pressure on the child to change his or her statement (SA 1).

(c) Children suffering due to stigmatization ( $n=4$; SC 2, SC 9 / SA 5, SA 8. The child is stigmatized by society and that is really hard to deal with (SC 9). The child will suffer from shame and its effects for his or her whole life (SA 5).

(d) Children recovering in the long-term despite the difficulty ( $n=3$; SC 5; SC 6 / SA 4). Children might get hurt when everything comes out, but the process will yield positive results for them. (SC 5).

The sub-themes executers of legal procedures harming the children, families acting in a punitive manner and children suffering due to stigmatization were endorsed by the majority of the participants. This serves as an indication of the strength of negative expectations about the impact that reporting will have on the child. On the other hand, the sub-theme children recovering in the long-term despite the difficulty was derived from the statements of three participants and indicates the belief that reporting would ultimately have a positive outcome.

\section{School Administrators' and School Counselors' Support Needs in Relation to Reporting Suspected CSA}

Two themes and sub-themes were derived from the answers given to the open-ended questions.

Theme 1. Providing support to the reporter. Three codes were defined under this theme:

(a) Ensuring the security of the reporter ( $n=7$; SC 6, SC 8 / SA 2, SA 3, SA 4, SA 5, SA 8). It is very important that the legislation takes guaranteed precautions against the security threats we face (SC 6). A good reporting method should be found to prevent the reporters from becoming the targets (SA 8).

(b) School administration and the judiciary cooperating with the reporter $(n=6$; SC 2, SC 3, SC 7, SC 8 / SA 1, SA 7). We need professionals, like school administrators, juvenile police and attorney generals, to show the same sensitivity and support us (SC 3). The presence of professionals who will support me and implement the laws with determination is the primary condition (SA 7).

(c) Information regarding the legal characteristics and process of reporting ( $n=3$; SA 2, SA 5, SA 7) School personnel should be taught about when to report and how to report in the most appropriate way possible (SA 2.)

The sub-themes under this theme, ensuring the security of the reporter and school administration and judiciary professionals cooperating with the reporter, are regarded as the most critical supports. 
The sub-theme information regarding the legal characteristics and process of reporting was derived from the statements of three participants.

Theme 2. Finding a basis for reporting. Three codes were defined under this theme.

(a) Children clearly stating that they have been exposed to CSA $(n=9 ; \mathrm{SC} 1, \mathrm{SC} 3, \mathrm{SC} 4, \mathrm{SC} 5, \mathrm{SC} 6, \mathrm{SC} 7, \mathrm{SC} 8$, SC 9/ SA 1). A clear statement by a child indicating that he or she is exposed to sexual abuse is sufficient for us to act (SC 4). I would submit a report if the child describes the situation clearly (SA 1).

(b) Finding clear evidence of CSA ( $n=5$; SA 2, SA 3, SA 4, SA 5, SA 6). Sexual abuse is the most severe accusation. It has severe consequences for both the child and the perpetrator. Thus, there should be clear evidence prior to reporting (SA 5).

(c) Having suspicion about children's behavior ( $n=1$; SC 2). If it is clearly evident from the child's behavior that sexual abuse has taken place and there are signs indicating that the child has been exposed to sexual abuse, such that it requires me to talk with them, then I would report my suspicions to the officers for investigation (SC 2).

The sub-theme children clearly stating that they have been exposed to CSA was derived from the statements of a school administrator and eight counselors. The sub-theme finding clear evidence of CSA was found to be a prerequisite for reporting. The sub-theme having suspicion about children's behaviors was referred to by just one school counselor, in a statement indicating that signs that a child has been exposed to sexual abuse would be sufficient to warrant reporting the case.

\section{Discussion}

The quantitative data showed that school administrators and counselors had high mean scores for the commitment to the reporting role factor, which indicates that school professionals tend to report when they have suspicions about CSA. However, the fact that the majority of the participants in this study who had reporting experience were counselors (74 school counselors, 19 school administrators) suggests that counselors' attitudes might be more positive than those of school administrators. Although school administrators and school counselors had high scores, the mean scores did not represent 'completely agree' to the liability of CSA reporting, which can be interpreted to mean that adult-centered dynamics prevented them from consistently acting to protect children, as Hamilton (2017) has argued. Therefore, the school counselors did not actually have more positive attitudes towards reporting CSA than the school administrators. In addition, the qualitative analysis revealed sub-themes with largely negative implications for participants' approach to the duty to report, as in a study by Bryant and Baldwin (2010); both analyses indicated that participants' attitudes regarding CSA reporting may not be as positive as their scores on the attitude scale showed. The children in a study by Moor (2017) said they did not believe that adults were committed to children's safety when significant safety problems arise. These children believed that adults were only attentive to the needs of other adults and institutions, which suggests that all institutional professionals have similar attitudes. The fact that school administrators' scores for confidence in the system's response to reports dimension were more positive than those of the counselors indicates that they trust the responses of the officials dealing with reports of CSA.

However, it is important to point out that counselors had more experience of the reporting process as they are the first people to learn about abuse cases and generally take responsibility for dealing with them. School counselors had less trust in the system, which indicates that their post-reporting experiences may be negative. Those who had reported an incident of CSA had significantly less trust in the relevant system than those who had never reported an incident of CSA, which supports the idea that negative experiences may be an important reference. Similarly, results from the study by Bryant and Baldwin (2010) indicate that the perceived inadequacy of the response system negatively affected reporting decisions. Analysis of responses related to commitment to the legal system revealed that only one administrator stated that the laws on CSA were executed, which is remarkable. The fact that there were no statements by other school administrators under this sub-theme suggests that administrators' commitment-related attitudes may not be as positive as they appeared to be in qualitative evaluations. On the other hand, it was also noteworthy that nearly all the participants who did not find the laws comprehensible and implementable were school counselors. Goldman and Padayachi (2005) found that most school counselors have general knowledge about the law on reporting suspected CSA cases, but only a few of them know what their obligations under the laws are. Hence the most realistic interpretation of this result may be that school counselors typically do not know the relevant laws or the abstract language of law. 
This result may be explained by findings showing that the reporting process is stressful (Lambie, 2005) and that the commitment to the legal system is low due to negative experiences, although there is evidence that counselors do make reporting decisions in accordance with the law. Most school administrators stated that they did not know the laws about reporting. This result implies that their responses to scale items related to commitment to the reporting system do not honest. Akgul's (2015) study also provided evidences that school administrators' do not know that reporting CSA is mandatory and therefore do nothing when they have suspicions. In addition the qualitative survey showcased the attitudes of a school counselor and administrator who had stated that they did not act although they knew their knowledge and use of the relevant laws could be related to their negative commitment to the reporting system and negative concerns about reporting.

Quantitative results from the study indicate that school administrators did not have any concerns about reporting (e.g. parents' negative reactions after reporting, having trouble reporting, and reluctance to report when evidence is not sufficient) and had more positive expectations about the outcomes of reporting than counselors. Although the school counselors did not express high levels of concern, this could change as they are more likely than administrators to find themselves in a position where they have to report a case of suspected CSA. However, the concern scores of those who had previously reported a case of CSA were significantly lower. So, it is fair to say that the participants' concerns about reporting diminished with reporting experience. Nevertheless our qualitative analysis revealed that all except two participants feared potential threats from the family of suspected victims of CSA and that this was a significant concern. This finding is consistent with earlier results from Bryant and Baldwin (2010).

The sub-themes referring to the negative consequences of reporting for children suggest that amongst our sample there was a strong expectation that the actions or reactions by the executers of the legal procedures, families and society might harm child victims of sexual abuse. This finding is consistent with a study of teachers (Kenny, 2001). The fact that there were three participants who stated that reporting would be best for the children even though it might have harmful consequences suggests that the high commitment to the reporting role indicated by the quantitative results was the result of the legal obligation to report. The strong expectation that reporting would ultimately have negative consequences for both reporter and child victim indicates that teachers and counselors may fail to report suspected CSA despite their legal obligation to do so. Qualitative findings may be explanatory to see which group of concern (reporter or child) is more important when submitting a report. Participants told us that their preconditions for reporting suspected CSA were security for reporters and support from school management and the judicial system. Cetinkaya (2015) reported similar results. This suggests that school professionals' concern is focused on those who report CSA rather than on the child victims. The fact this theme did not encompass any statements about the need for effective protection for suspected victims of CSA supports the idea that self-protection was a higher priority for our sample. This is consistent with other recent studies (Hamilton, 2017; Moor, 2017) which also showed that adult-centered dynamics can be a great barrier even when it comes to protecting children who are extremely vulnerable as a result of sexual abuse.

Another remarkable outcome is that eight school counselors said that they would only report CSA if the abuse disclose by the child; school administrators also regarded clear evidence of abuse as a prerequisite of reporting. This suggests that all the school counselors (except one) were aware of the mandatory responsibility defined in Article 279 of the TPC. But, other studies have also found that professionals are reluctant to report in cases where this is a lack of evidence (Bryant et al., 2005; Zellman, 1990). School administrators tend to abstain from reporting without clear evidence, despite the law; this is probably due to their lack of knowledge or understanding of the laws related to CSA. Another logical explanation for the reluctance of administrators to report sexual abuse, despite the threat of imprisonment for failure to report, is that there is no strict educational system-wide policy on reporting of CSA.

The limited number of school principals in the quantitative sample who had reported cases supports these two explanations. Similarly, Zellman (1990) suggested that knowledge about mandatory reporting and a strict policy on reporting are predictors of school administrators' attitude to CSA reporting.

It is remarkable that only one counselor considered that children displaying signs of abuse signs a basis for reporting suspected CSA and as a prerequisite of reporting in cases where there is no statement from the suspected victim. This response may be related to the training counselors receive on this issue. 
It is critical that training on CSA includes the statistic (Alaggia, 2004, 2005) that approximately 30-60\% of sexually abused children state that they do not remember or cannot speak about what they faced on account on account of their fears and trauma (Lyon \& Ahern, 2011).

The main benefit of training on CSA might be that it enables professionals to recognize observable signs of CSA and gives them the confidence to report suspected abuse, whether the suspicions are based on observation or interviews with the child. The lack of commentary by many school counselors who made statements that fell under this sub-theme indicates that there is a tendency to abstain from reporting when it is not deemed mandatory by law. The themes uncovered in this study indicate the need to provide thorough training on the observable signs of CSA, the ways in which interviews should be conducted to encourage children to disclose incidents of CSA, and the reporting duties and procedures for school personnel. In addition, the qualitative results indicate that at present school counselors do not find the laws clear or comprehensible, which suggest further training is needed in this area. As Mathews (2014) noted, it is very important to make the laws on mandatory reporting of CSA clearer so that they can be easily understood.

The quantitative data indicated that training on CSA did not affect attitude to reporting, which may be due to the inadequacy of current training programs. It has been suggested (Reiniger et al., 1995) that inadequate training is the main reason for failure to report child abuse. The fact that positive changes have been reported following adequate training on CSA (Hawkins \& McCallum, 2001; Ridgway, 2005) suggests that the training received by the participants in this study may have been inadequate.

Daro (2011) reported that child sexual assault prevention programs designed and implemented in the USA in the 1980s had a positive impact on attitudes towards reporting. Daro attributed the success of these programs to their content, which included instructions for parents and school personnel, along with details about how to report in cases when sexual abuse may be present (Daro, 2011). However, a study by Hawkins and McCallum (2001) indicated that training does not necessarily guarantee that suspected abuse will be reported, because some teachers will still prioritize their personal needs, which is remarkable. Given that the participants in this study who had previously reported suspected CSA stated that their personal safety was their primary concern supports the notion that on its own, training may not be enough to ensure that school personnel fulfill their obligation to report. There is a need to consider this dynamic in order to make progress in the fight to protect children against CSA. For this reason, efforts to protect children from CSA must include actions in three categories: children, adults and organizations. These categories must be studied, modified, and regularly re-adjusted to reach child protection goals (Hamilton, 2017). To this end, a combination of educational and legal regulations that ensure the security of reporters would generate positive change. In addition, the implementation of a strict school policy that lays out clear instructions for reporting might also have a positive impact on reporting.

With the educational programs to be prepared by taking the results of this study into consideration it is important, in terms of fostering positive changes, that school administrators should be informed of the ways they can take part in the process with counselors to prevent CSA. Moreover, ensuring that school administrators and counselors who have submitted their reports share their experiences with colleagues might help to allay concerns amongst these professions and strengthen commitment to the reporting system.

The original plan for this study was to collect qualitative data via interviews, before administering the quantitative instruments. However, the District Directorate of National Education and school administrators did not agree to audio recording of interviews and insisted that written answers be provided to the items. This meant that the qualitative data were limited to the short, written answers provided in responses to the open-ended questions in the attitude questionnaire. Similar studies suggest that collecting qualitative data via focus group discussions ensures that validity issues are minimized, as more comprehensive data can be obtained and data diversity is achieved. In addition, collecting data on the factors that affect reporting decisions through observations and interviews relating to real-life cases of suspected CSA may yield clearer results. This study may be a step towards better understanding of the support school administrators and school counselors need in relation to CSA reporting. This research agenda should be pursued further in order to generate recommendations for more effective child protection policies and practices. 


\section{References}

Akgul, E. (2015). A study about reporting status of CSA by the staff working in preschool education centers [Okul öncesi eğitim kurumlarinda çalişan personelin cinsel istismar bildirim durumları]. (Unpublished master's thesis). Hacettepe University, Ankara.

Aksel, E.S., \& Irmak, T.Y. (2015). Teachers' knowledge and experiences in child sexual abuse. Ege Journal of Education, 16(2), 373-391.

Alaggia, R. (2004). Many ways of telling: Expanding conceptualizations of child sexual abuse disclosure. Child Abuse \& Neglect, 28, 1213-1227.

Alaggia, R. (2005). Disclosing the trauma of child sexual abuse: a gender analysis. Journal of Loss and Trauma, $10,453-470$.

Allnock, D. (2010) Children and young people disclosing sexual abuse: An introduction to the research. [Online] Available: http://www.childmatters.org. (June 15, 2016)

Bryant, J.K. (2009). School counselors and child abuse reporting: A national survey. Professional School Counseling, 12, 333-342.

Bryant, J. K., \& Baldwin, P. A. (2010). School counselors' perceptions of mandatory reporter training and mandatory reporting experiences. Child Abuse Review, 19, 172-186.

Bryant, J., \& Milsom, A. (2005). Child abuse reporting by school counselors. Professional School Counseling, 9(1), 63-71.

Cetinkaya, R.S. (2014). Ethical dilemmas of Turkish counselors: A critical incidents study. Online first. British Journal of Guidance \& Counseling, 43(4), 476-491.

Cetinkaya, R.S. (2015). Turkish school counselors' experiences of reporting child sexual abuse: a brief report. Journal of Child Sexual Abuse, 24, 908-921.

Daro, D. (2011). Prevention of child abuse and neglect. In J. E. B. Myers (Eds), The APSAC handbook on child maltreatment ( $3^{\text {rd }}$ edn., pp. 17-37). Newbury Park, CA: Sage.

Erbas, R. (2015). Liability of health professionals to report an offence in Turkish law and comparative law. Istanbul: Oniki Levha.

Eren Gümüs, A., \& Gümüs, M.A. (2013). Ethics and law in psychological counseling [Psikolojik danışmada etik ve hukuk]. Istanbul: Vedat.pp.128.

Goldman, J.D.G., \& Padayachi, U.K. (2000). School counsellors' knowledge of the nature of child sexual abuse and proceedures and laws. Journal of Psychologists and Counsellors in Schools, 10(1), 1-18.

Goldman, J.D.G., \& Padayachi, U.K. (2002a). Factors influencing school counsellors' decision not to report child sexual abuse. Children Australia, 27(1), 28-37. Goldman, J.D.G., \& Padayachi, U.K. (2002b). School counselors' attitudes and beliefs about child sexual abuse. Journal of Family Studies, 8, 53 -73.

Goldman, J.D G, \& Padayachi, U.K. (2005). Child sexual abuse reporting behaviour by school counsellors and their need for further education. Health Education Journal, 64(4), 302-322.

Greene, J.C. (2005). The generative potential of mixed methods inquiry. International Journal of Research \& Method in Education, 28(2), 207 - 211.

Hamilton, M.A. (2017). The barriers to a national inquiry into child sexual abuse in the United States. Child Abuse \& Neglect, 74, 107-110.

Hawkins, R., \& McCallum, C. (2001). Mandatory notification training for suspected child abuse and neglect in South Australian schools. Child Abuse \& Neglect, 25(12), 16-1625.

Hermann, M.A. (2002). A study of legal issues encountered by school counselors and perceptions of their preparedness to respond to legal challenges. Professional School Counseling, 6(1), 12.

Kenny, M.C. (2001). Child abuse reporting: Teachers' perceived deterrents. Child Abuse \& Neglect, 25, 81-92.

Kenny, M.C., \& McEachern, A.G. (2002). Reporting suspected child abuse: A pilot comparison of middle and high school counsellors and principals. Journal of Child Sexual Abuse, 11(2), 59-75.

Koca, M. (2012). Notice liability in child abuse. [Çocuk istismarında ihbar yükümlülügü]. İnönü Üniversitesi Hukuk Fakültesi Dergisi, 3(1), 113-127.

Lambie, G.W. (2005). Child abuse and neglect: A practical guide for professional school counselors. Professional School Counseling, 8(3), 249-258.

Leech, N.L., \& Onwuegbuzie, A.J. (2009). A typology of mixed methods research designs. Quality \& Quantity, 43, 265-275. 
Lyon, T.D., \& Ahern, E.C. (2011). Disclosure of child sexual abuse. In J.E B.Myers (Ed.), The APSAC handbook on child maltreatment ( $3^{\text {rd }}$ ed., pp. 233-252). CA: Sage.

Mathews, B. (2014). Mandatory reporting laws and identification of child abuse and neglect: consideration of differential maltreatment types, and a cross-jurisdictional analysis of child sexual abuse reports. Social Sciences 3, 460-482.

Miles, M,B., \& Huberman, A.M. (1994). Qualitative data analysis: An expanded Sourcebook. (2 ${ }^{\text {nd }}$ ed). Thousand Oaks, CA: Sage

Moore, T.P. (2017). Children and young people's views on institutional safety: it's not just because we're little. Child Abuse \& Neglect, 74, 73-85.

Paine, M.L., \& Hansen, D. (2002). Factors influencing children to self-disclose sexual abuse. Clinical Psychology Review, 22, 271-295. [Online] Available: http://digitalcommons.unl.edu/cgi/viewcontent.cgi (May 23, 2016).

Raykov, T., \& Marcoulides, G.A. (2006). Fundamentals of structural equation modeling. A first course in structural equation modeling ( $2^{\text {nd }}$ edn.). London: Lawrence Erlbaum Associates.

Reiniger, A., Robison, E., \& McHugh, M. (1995). Mandated training of professionals: A means for improving reporting of suspected child abuse. Child Abuse \& Neglect, 19(1), 63-69.

Ridgway, A.H.K. (2005). Teachers' knowledge of child abuse reporting laws. (Unpublished doctoral dissertation). California State University, Long Beach, CA.

Simsek, H., \& Yildirim, A. (2003). Qualitative research methods in social sciences.[Sosyal Bilimlerde Nitel Araştırma Yöntemleri]. Ankara: Seckin Publishing.

Smallbone, S. W., \& Wortley, R. K. (2001). Child sexual abuse: Offender characteristics and modus operandi (Vol. 193). Canberra: Australian Institute of Criminology. [Online] Available: www.aic.gov.au (April 3, 2016)

Sokullu-Akinci, F. (2008). Victimology [Viktimoloji] (2 ${ }^{\text {nd }}$ edn). Istanbul: Beta.pp.57.

Unver, Y. (2012). Offences against the judiciary (Adliyeye karşl suçlar). ( ${ }^{\text {rd }}$ edn.). Ankara: Seckin.

Walsh, K. M., Rassafiani, M., Mathews, B. P., Farrell, A., \& Butler, D. A. (2010). Teachers' attitudes toward reporting child sexual abuse: Problems with existing research leading to new scale development. Journal of Child Sexual Abuse, 19(3), 310-336.

Walsch, K., Rassafiani, M., Mathews, B. Farrel, A., \& Butler, D. (2012). Exploratory factor analysis and psychometric evaluation of the teacher reporting attitude scale for child sexual abuse. Journal of Child Sexual Abuse, 21(5), 489-506

Zellman, G. L. (1990). Linking schools and social services: The case of child abuse reporting. Educational Evaluation and Policy Analysis, 12(1), 41-55. [Online] Available: http://www.dtic.mil/dtic/tr/fulltext/u2/a257667.pdf: (April 23, 2016) 